\title{
Effect of PPG-PEG-PPG Co-Polymer on Zn-Cr Alloy Electrodeposition
}

\author{
Tzvetanka Boiadjieva-Scherzer \\ CEST Centre of Electrochemical Surface Technology GmbH, Viktor-Kaplan-Straße 2, 2700 Wiener Neustadt, Austria
}

\begin{abstract}
The $\mathrm{Zn}-\mathrm{Cr}$ alloy coatings turned out to be an alternative to the $\mathrm{Zn}$ coatings for corrosion protection of steel. Following the development of the high speed deposition of $\mathrm{Zn}-\mathrm{Cr}$ on steel sheets for the automotive industry adaptation of the deposition process for automotive small parts, structural components, etc. would be a further achievement. In this respect, the effect of the deposition conditions and particularly that of PPG-PEG-PPG co-polymer additive, average $\mathrm{M}_{n}$ 2,000 on the Cr co-deposition with Zn was investigated. Cyclic voltammetry and galvanostatic deposition on rotating cylinder electrodes and on flat samples were applied. It was found that $\mathrm{Cr}$ co-deposition and dense layer formation could be obtained at a low concentration of the co-polymer additive ( 0.1 $\mathrm{g} \cdot \mathrm{L}^{-1}$ ) and in the low current density range (5-20 A $\cdot \mathrm{dm}^{-2}$ ). Coatings were characterized by using XRFA (X-ray fluorescence analysis), SEM (Scanning electron microscopy), EDX (Energy dispersive X-ray) and XRD (X-ray diffraction). The Cr content in the alloys is up to 33 mass\% depending on deposition conditions. $\Gamma-(\mathrm{Zn}, \mathrm{Cr})$ phase, a solid solution with a body centered cubic sub-cell and hexagonal $\eta-(\mathrm{Zn}, \mathrm{Cr})$ phase were detected.
\end{abstract}

Key words: Electrodeposition, $\mathrm{Zn}$-Cr alloy coatings, co-polymer additive, SEM (Scanning electron microscopy) Zn-Cr.

\section{Introduction}

The $\mathrm{Cr}$ co-deposition with $\mathrm{Zn}$ requires the use of additives to proximate the deposition potentials and to obtain coatings with well-defined, targeted properties. Nonionic polymers, polyethyleneglycol (PEG) with different molecular mass $(400,1,500,6,000$ and 20,000) and polypropyleneglycol (PPG 620) were previously used in electrolytes for $\mathrm{Zn}-\mathrm{Cr}$ alloy deposition. The optimized electrolyte composition for high speed electrodeposition on steel sheets contains PEG 6,000. The comprehensive investigations on the $\mathrm{Zn}-\mathrm{Cr}$ alloy electrodeposition showed that the polyoxialkylene compounds facilitate the $\mathrm{Cr}$ co-deposition with $\mathrm{Zn}$ by raising the overpotential for the $\mathrm{Zn}$ deposition [1-5]. When using PEG 1,500 for example, the co-deposition takes place at a potential, of about $-1.95 \mathrm{~V}$ (vs. $\mathrm{Hg} / \mathrm{Hg}_{2} \mathrm{SO}_{4}$ ), which in galvanostatic conditions is reached at a current density

Corresponding author: Tvetanka Boiadjieva-Scherzer, Dr., senior researcher, research fields: electrodeposition \& dissolution of metals and alloys, composite coatings, surface \& bulk properties of metals and alloys, corrosion. higher than $15 \mathrm{~A} \cdot \mathrm{dm}^{-2}$. The strong inhibition of the $\mathrm{Zn}$ bulk deposition has been related to polymer-electrode interactions [2-5]. Investigations with PPG 620 showed co-deposition of $\mathrm{Zn}$ and $\mathrm{Cr}$ at a less negative potential of $-1.8 \mathrm{~V}$ (vs. $\mathrm{Hg} / \mathrm{Hg}_{2} \mathrm{SO}_{4}$ ) and a possibility to deposit alloy coatings containing up to 23 mass $\%$ $\mathrm{Cr}[6]$.

The successful alloy deposition from electrolytes containing PEG or PPG brought the attention to the polypropylenglykol-block-polyethylenglykol-block-p olypropylenglykol co-polymer (PPG-PEG-PPG). In the present work the effect of PPG-PEG-PPG, average $\mathrm{M}_{\mathrm{n}} 2,000$ on the $\mathrm{Cr}$ co-deposition with $\mathrm{Zn}$ was investigated in search of an electrolyte composition appropriate for batch galvanizing. In the course of the experiments coatings appearance, $\mathrm{Cr}$ content and thickness as well as roughness, morphology and phase composition for selected samples were followed.

\section{Experimental Setup}

An electrolyte with a base composition: $172 \mathrm{~g} \cdot \mathrm{L}^{-1}$ $\mathrm{ZnSO}_{4} \cdot 7 \mathrm{H}_{2} \mathrm{O}+71 \mathrm{~g} \cdot \mathrm{L}^{-1} \quad \mathrm{Na}_{2} \mathrm{SO}_{4}+200 \mathrm{~g} \cdot \mathrm{L}^{-1}$ 
$\mathrm{KCr}\left(\mathrm{SO}_{4}\right)_{2} \cdot 12 \mathrm{H}_{2} \mathrm{O}$ (sodium sulfate electrolyte,

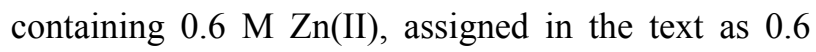
$\mathrm{SSE}$ ) was selected for the present investigations. The composition without $\mathrm{Cr}(\mathrm{III})$ is commonly used for $\mathrm{Zn}$ deposition on steel strips for the automotive industry. The $\mathrm{Zn}$ (II): $\mathrm{Cr}$ (III) ratio in the electrolyte was varied from 0.4 to $0.8 \mathrm{M}$ for $\mathrm{Zn}$ (II) (0.4 SSE, 0.8 SSE, respectively) and from 0.2 to $0.4 \mathrm{M}$ for $\mathrm{Cr}(\mathrm{III})$. The $\mathrm{pH}$ of the electrolyte was 2.0 , adjusted with sulphuric acid. PPG-PEG-PPG, average $\mathrm{M}_{\mathrm{n}} 2,000$ (50 mass\% PEG) in concentrations from 0.05 to $1.0 \mathrm{~g} \cdot \mathrm{L}^{-1}$ was added to the electrolyte. A combined PPG-PEG-PPG and glycine additive was used, as well. The glycine concentrations were 0.25 and $0.5 \mathrm{M}$.

The alloy deposition was investigated by using cyclic voltammetry in a three-electrode cell having a volume of $50 \mathrm{ml}$, reference $\mathrm{Hg} / \mathrm{Hg}_{2} \mathrm{SO}_{4}$ electrode, $\mathrm{Pt}$ working electrode with a surface area of $0.2 \mathrm{~cm}^{2}$ and a Pt counter electrode. The scanning rate was $25 \mathrm{mV} \cdot \mathrm{s}^{-1}$. The initial potential was the OCP (Open circuit potential) and the polarization was first in negative direction; the end potential was $+1.6 \mathrm{~V}$. All experiments were carried out using a potentiostat/galvanostat model 263A (EG\&G Princeton Applied Research, USA) and software SoftCorr II.

Galvanostatic electrodeposition was carried out on rotating steel cylinder electrodes (RCE) with a working area of $10.7 \mathrm{~cm}^{2}$ in a glass cell with an electrolyte volume of $1 \mathrm{~L}$. The rotational speed was varied from 500 to $3,000 \mathrm{rpm}$. Potentiostat/galvanostat model PG30A (Jaissle, Germany) and Ecm Win software were used for these experiments. Cathode current efficiencies for the alloy deposition were calculated by using the measured thickness of the coatings, as follows:

$$
m_{\text {exper. }}=\rho \cdot s \cdot d
$$

where, $\rho$ is the density of the $\mathrm{Zn}-\mathrm{Cr}$ alloy $\left[\mathrm{g} / \mathrm{cm}^{3}\right], s$ is the surface area $\left[\mathrm{cm}^{2}\right]$ and $d$ is the thickness of the coating $[\mathrm{cm}]$.

$$
m_{\text {theoret. }}=\left(\varepsilon_{\mathrm{Zn}}^{2+} \cdot \% \mathrm{Zn}+\varepsilon_{\mathrm{Cr}}^{3+} \cdot \% \mathrm{Cr}\right) \cdot I \tau
$$

where, $\varepsilon_{Z n}{ }^{2+}$ is the electrochemical equivalent of $\mathrm{Zn}^{2+}$ [g/Ah], $\varepsilon_{C r}{ }^{3+}$ is the electrochemical equivalent of $\mathrm{Cr}^{3+}$ [g/Ah], $I$ is the applied current $[\mathrm{A}]$ and $\tau$ is the deposition time [s].

$$
\eta_{\text {alloy }}=\left(m_{\text {exper. }} / m_{\text {theoret. }}\right) \cdot 100, \%
$$

where, $\eta_{\text {alloy }}$ is the cathode current efficiency for the alloy deposition [\%].

Galvanostatic electrodeposition on flat mild steel samples with a surface area of $2 \mathrm{~cm}^{2}$ was performed as well. Electrolyte agitation by air and rack movement was applied for selected electrolyte compositions.

The cathodic current density was within the $5-125$ $\mathrm{A} \cdot \mathrm{dm}^{-2}$ range; the deposition time was within $20-300$ $\mathrm{s}$ range and the electrolyte temperature was within 23 (the room temperature) $-60^{\circ} \mathrm{C}$ range.

The $\mathrm{Cr}$ content in the alloy coatings and the coatings thickness were determined by using XRFA (X-ray fluorescence analysis) (Fischerscope XDL-B, Software WinFTM 6.09). The elemental composition was also measured by EDX (Energy dispersive X-ray) spectrometer supported with Genesis software (USA).

The surface roughness of $\mathrm{Zn}$-Cr coatings was measured by means of a Hommel tester (T1000, Germany).

The surface morphology was analyzed by XL 30 ESEM (Environmental scanning electron microscope) with field emission gun (FEI Co., Netherlands).

Phase characterization of samples by XRD (X-ray diffraction) technique was performed using an X'Pert Powder diffractometer (Philips, Netherlands) at $40 \mathrm{kV}$ and $30 \mathrm{~mA}$ in conventional Bragg-Brentano geometry. The measurements were performed in a step-scan mode over the range $5-120^{\circ} 2 \theta$ with a step size of $0.05^{\circ}$ and counting time of $6 \mathrm{~s} \cdot \mathrm{step}^{-1}$. The range of $30-80^{\circ} 2 \theta$ is presented.

\section{Results and Discission}

\subsection{Cyclic Voltammetry}

Fig. 1 shows comparison of voltammograms in the basic 0.6 SSE in absence and presence of PEG 6,000 


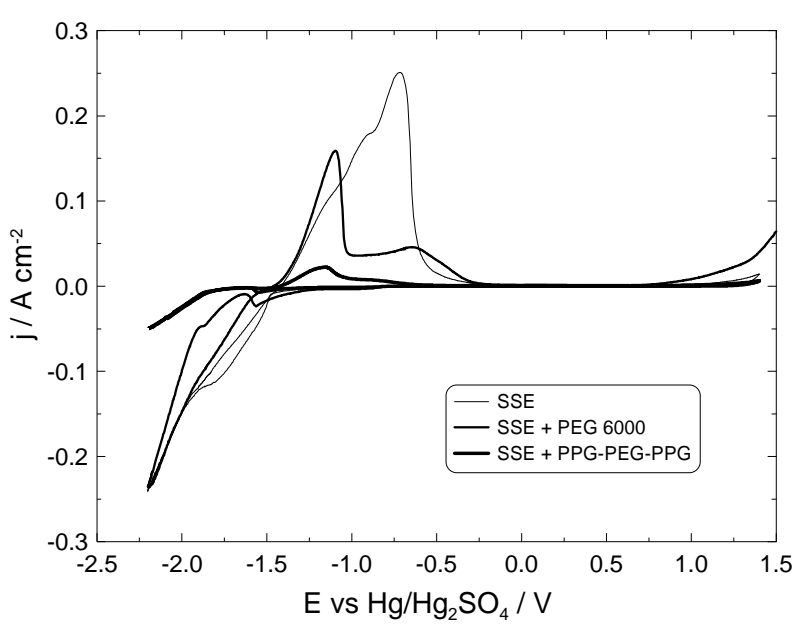

Fig. 1 Voltammograms showing the effect of the additives on the deposition and dissolution of $\mathrm{Zn}-\mathrm{Cr}$. Initial potential: OCP, scan rate: $25 \mathrm{mV} \cdot \mathrm{sec}^{-1}$.

or PPG-PEG-PPG at room temperature. The PEG strongly suppresses the bulk deposition (with about $250 \mathrm{mV}$ ), as at more negative potentials the polarization effect is reduced and in the bordering case of the reverse potential of $-2.2 \mathrm{~V}$, the curve overlaps that obtained from the electrolyte without an additive. In the presence of PEG, the co-deposition of $\mathrm{Cr}$ and $\mathrm{Zn}$ are established at a potential of about $-2.0 \mathrm{~V}$. In galvanostatic regime this potential value is reached at a current density of $15 \mathrm{~A} \cdot \mathrm{dm}^{-2}$ [3]. Presumably, the inhibition of the $\mathrm{Zn}$ reaction, enabling $\mathrm{Cr}$ co-deposition, is related to a potential dependent PEG adsorption, most probably through hydrogen bonding $[2,5]$. Moreover, it is likely that the additive further controls the growth rate by blocking surface processes [7-9]. J. Heyrovsky deduced that electrolytic acceptance of more than one electron is not simultaneous but consecutive and in case of $\mathrm{Zn}$ deposition, the second electron is acquired through disproportionation, i.e.:

$$
2 \mathrm{Zn}^{+} \rightarrow \mathrm{Zn}+\mathrm{Zn}^{2+}
$$

the rate of which determines the rate of electrodeposition; this is retarded by films of adsorbed molecules [9].

The PPG-PEG-PPG co-polymer causes stronger polarization in comparison to PEG (of about $400 \mathrm{mV}$ ) in the bulk deposition region which is kept and even enhanced at higher negative potentials (Fig. 1). It could be suggested that the co-polymer controls the deposition process in a similar manner to that of PEG. However, due to the hydrophobic properties of the co-polymer (determining the hydration state and the interactions of the molecules), from the viewpoint of surface energy, a larger adsorption strength of co-polymer molecules compared to that of PEG (hydrophilic properties) is expected [10].

It is worth emphasizing that a high polarization of the deposition process is reached in the low current density range (Fig. 1).

The anodic part of the voltammograms indicates different alloy composition of the cathodically deposited layers. Considering the anodic maxima, all in the range of active dissolution of $\mathrm{Zn}$ and $\mathrm{Cr}$ and based on previous data $[4,11-13]$ it could be summarized that: 1) in the electrolyte without additives, the maximum is mainly due to $\mathrm{Zn}$ dissolution; 2) the two maxima in the electrolyte containing $\mathrm{PEG}$ are also mainly related to $\mathrm{Zn}$ dissolution, but from different $(\mathrm{Zn}, \mathrm{Cr})$ phases [11, 13]; 3) the dissolution of $\mathrm{Cr}$ is also possible, but it is difficult to distinguish. A contribution from diffusion limitations of the dissolution process has to be taken into account [12], as well in order to explain peak separation. The smaller area of the anodic maximum in the electrolyte containing the co-polymer demonstrates a smaller mass of the deposit due to the lower current density reached during the cathodic polarization and possibly due to a lower current efficiency of deposition in comparison to that in PEG containing electrolyte. It could be suggested that the deposit from the co-polymer containing electrolyte is a single phase (see Section 3.2.3).

\subsection{Galvanostatic Deposition on RCE}

The effect of the PPG-PEG-PPG additive on the $\mathrm{Zn}-\mathrm{Cr}$ alloy deposition was routinely investigated under galvanostatic conditions by using RCE. It is known that the controlled mass transport, i.e. the 
defined thickness of the diffusion layer is an important factor for the deposition of homogeneous alloy coatings. The effect of the deposition parameters on the alloys composition, structure and appearance were followed.

The results from experiments that performed with the $0.4 \mathrm{SSE}$ composition and at elevated temperature of $40{ }^{\circ} \mathrm{C}$ are presented in this Section.

The electrolyte without an additive produces layers with $\mathrm{Cr}$ content of about 3 mass\% and thickness of about $20 \mu \mathrm{m}$ (Table 1).

Significant effect of the co-polymer on the $\mathrm{Cr}$ incorporation in the coatings and the thickness of the layers are observed when increasing its concentration from $0.05 \mathrm{~g} \cdot \mathrm{L}^{-1}$ to $0.1 \mathrm{~g} \cdot \mathrm{L}^{-1}$. Further increase of the co-polymer concentration up to $1 \mathrm{~g} \cdot \mathrm{L}^{-1}$ does not lead to an increase of the $\mathrm{Cr}$ content in the alloy. The values of the coatings' thickness that obtained by XRFA are also similar.

Fig. 2 presents the morphology of $\mathrm{Zn}$-Cr coatings from the basic electrolyte and from the basic electrolyte containing different amounts of the co-polymer additive.

The coatings deposited from the additive free electrolyte show the typical for $\mathrm{Zn}$ large hexagonal crystallites (Fig. 2a). The morphology of the coatings from the electrolytes containing different concentration of the additive is alike (Figs. $2 b$ and $2 c$ ). The layers are composed of densely packed polycrystalline particles forming agglomerates with irregular shape and size in the micro-meter range. Higher density of the layer from the electrolyte with the higher co-polymer concentration is to note.

\subsubsection{Effect of the Current Density}

Table 2 shows the effect of the current density on the $\mathrm{Cr}$ content in the alloy at different co-polymer concentrations in the electrolyte.

Despite of the increase of the current density, twice, from 50 to $100 \mathrm{~A} \cdot \mathrm{dm}^{-2}$ close values for the $\mathrm{Cr}$ in the alloys are obtained. The surface morphology of the layers is similar as well (Fig. 3). At a current density of $50 \mathrm{~A} \cdot \mathrm{dm}^{-2}$, for instance (Table 2, column: 0.125 $\left.\mathrm{g} \cdot \mathrm{L}^{-1}\right)$ the coating thickness is about $8 \mu \mathrm{m}$ over $14 \mu \mathrm{m}$, at $75 \mathrm{~A} \cdot \mathrm{dm}^{-2}$ to $20 \mu \mathrm{m}$, at $100 \mathrm{~A} \cdot \mathrm{dm}^{-2}$. Variations of the deposition time within the 60-106 s range also did not significantly affect the alloy composition and morphology, but the layer thickness, suggesting uniform distribution of $\mathrm{Cr}$ in depth. A mean surface roughness $(\mathrm{Ra})$ of $0.5 \mu \mathrm{m}$ was measured for the coatings presented in Fig. 3.

The independence of the $\mathrm{Cr}$ content from the current density and the additive concentration, above certain values, indicates limiting conditions for the $\mathrm{Cr}$ co-deposition. The boundary concentration of about 30 mass $\% \mathrm{Cr}$ could be related to the crystal structure of the layer (see Section 3.2.3). Previous investigations on the dependence of the unit cell parameter from the relative atomic content of $\mathrm{Cr}$ in the bec $\Gamma-(\mathrm{Zn}, \mathrm{Cr})$ phase pointed out at a boundary concentration of about 33 at. $\% \mathrm{Cr}$ in the $\Gamma$ - phase at the initial stages of deposition from an electrolyte without agitation [4]. Apparently, the electrolyte flow promotes a uniform layer growth.

3.2.2 Effect of the Combined Additive PPG-PEG-PPG and Glycine

Glycine added to the base electrolyte as an only

Table 1 Effect of the concentration of PPG-PEG-PPG on the Cr content in Zn-Cr alloys and on the thickness of coatings deposited on steel RCE at $100 \mathrm{~A} \cdot \mathrm{dm}^{-2}, 1,000 \mathrm{rpm}$ for $60 \mathrm{~s}, 40{ }^{\circ} \mathrm{C}$.

\begin{tabular}{lll}
\hline PPG-PEG-PPG concentration $\left(\mathrm{g} \cdot \mathrm{L}^{-1}\right)$ & Cr content $(\operatorname{mass} \%)$ & Thickness $(\mu \mathrm{m})$ \\
\hline 0 & 2.5 & 20 \\
0.05 & 5 & 19 \\
0.10 & 33 & 11 \\
0.125 & 32.7 & 12 \\
0.25 & 33.5 & 12 \\
1.00 & 32.5 & 14 \\
\hline
\end{tabular}




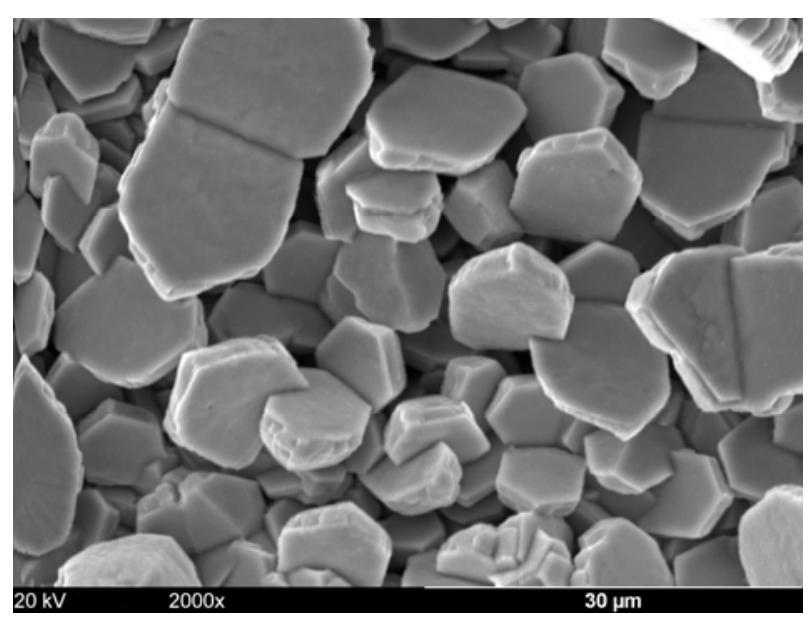

(a)

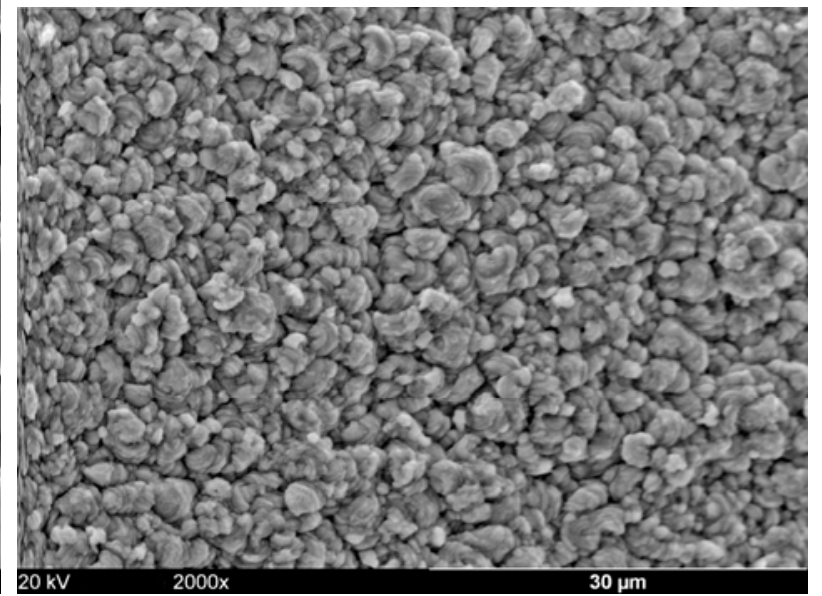

(b)

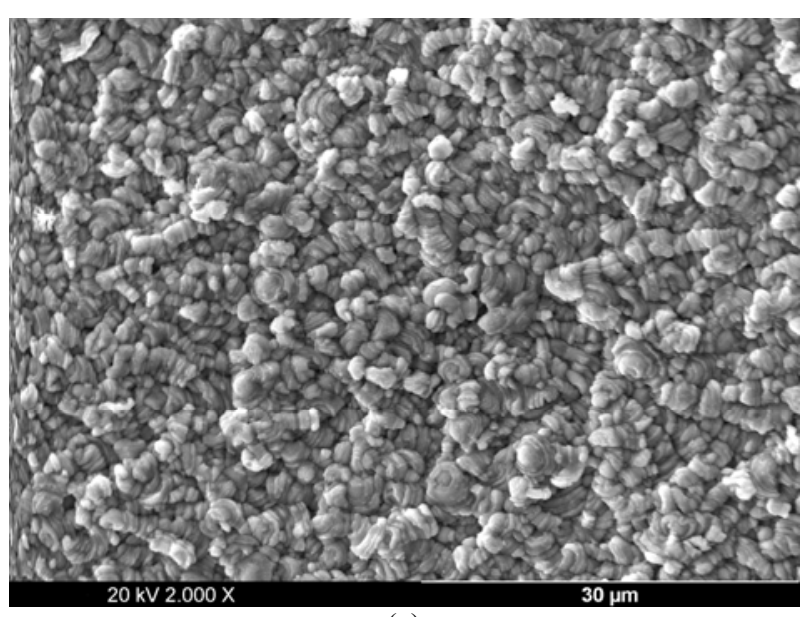

(c)

Fig. 2 Morphology of coatings deposited at $100 \mathrm{~A} \cdot \mathrm{dm}^{-2}, 1,000 \mathrm{rpm}$ for $60 \mathrm{~s}$ from: (a) $0.4 \mathrm{SSE}$, (b) $0.4 \mathrm{SSE}+0.125 \mathrm{~g} \cdot \mathrm{L}^{-1}$ PPG-PEG-PPG and (c) 0.4 SSE + 1.0 g. $\mathrm{L}^{-1}$ PPG-PEG-PPG. (a) to (c) is top to bottom.

Table 2 Effect of the current density and concentration of PPG-PEG-PPG on the Cr content in Zn-Cr alloys deposited on steel RCE at 1,000 rpm for $106 \mathrm{~s}, 40^{\circ} \mathrm{C}$.

\begin{tabular}{lllll}
\hline & $\mathrm{g} \cdot \mathrm{L}^{-1}$ & $0.125 \mathrm{~g} \cdot \mathrm{L}^{-1}$ & $0.25 \mathrm{~g} \cdot \mathrm{L}^{-1}$ & $1.0 \mathrm{~g} \cdot \mathrm{L}^{-1}$ \\
\hline Current density $\left(\mathrm{A} \cdot \mathrm{dm}^{-2}\right)$ & $\mathrm{Cr}(\operatorname{mass} \%)$ & $\mathrm{Cr}(\operatorname{mass} \%)$ & $\mathrm{Cr}(\operatorname{mass} \%)$ & $\mathrm{Cr}(\operatorname{mass} \%)$ \\
25 & - & 20 & 20 & - \\
50 & 30 & 30 & 30 & 30 \\
75 & 30.5 & 32 & 32.5 & 30.5 \\
100 & 32 & 33.5 & 33 & 32.5 \\
\hline
\end{tabular}

additive does not facilitate the alloy deposition, but stabilizes the electrolyte and contributes to a better appearance of the deposits [6]. The addition of glycine to the PPG-PEG-PPG containing electrolyte enables the deposition of $\mathrm{Zn}-\mathrm{Cr}$ coatings containing up to about 20 mass\% Cr (Table 3). Both the increase of the current density above $75 \mathrm{~A} \cdot \mathrm{dm}^{-2}$ and of the co-polymer concentration from 0.1 to $0.125 \mathrm{~g} \cdot \mathrm{L}^{-1}$ and higher do not result in an increase of the $\mathrm{Cr}$ content in the layer.

It is worth mentioning that the current input required to reach the "boundary" amount of $\mathrm{Cr}$ in the coatings (of about 20 mass $\% \mathrm{Cr}$ ) is higher than that from the electrolyte containing only PPG-PEG-PPG. This could be related to metal ions-glycine complexation and glycine-electrode surface interactions [14], in addition to the existing interactions caused by the co-polymer, resulting in an 


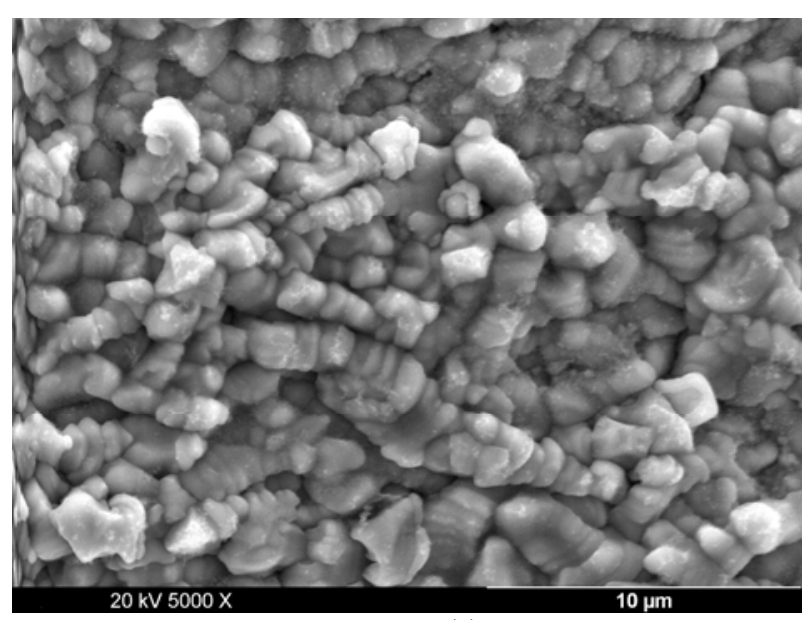

(a)

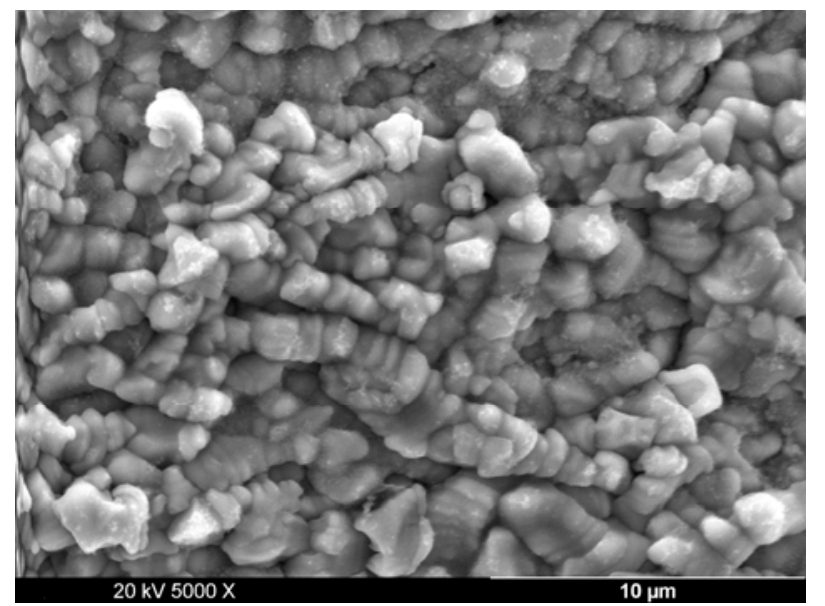

(b)

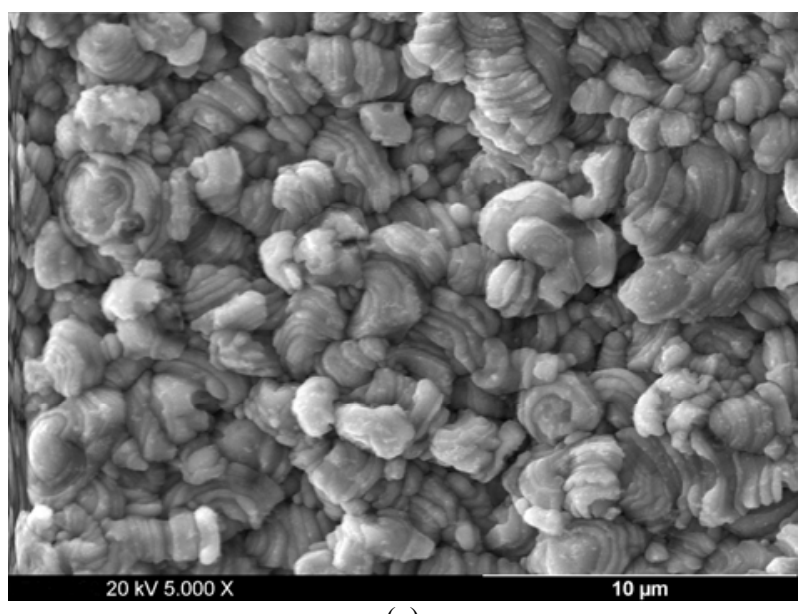

(c)

Fig. 3 Morphology of coatings deposited from 0.4 SSE $+1.0 \mathrm{~g} \cdot \mathrm{L}^{-1}$ PPG-PEG-PPG at 1,000 rpm for $80 \mathrm{~s}:$ (a) $50 \mathrm{~A} \cdot \mathrm{dm}^{-2}$, (b) 75 $A \cdot \mathrm{dm}^{-2}$ and (c) $100 \mathrm{~A} \cdot \mathrm{dm}^{-2}$. (a) to (c) from top to bottom.

Table 3 Effect of the current density and the rotational speed on the $\mathrm{Cr}$ content in $\mathrm{Zn}$-Cr alloys and on the thickness of coatings deposited on steel RCE for $106 \mathrm{~s}, 40^{\circ} \mathrm{C}$.

\begin{tabular}{llll}
\hline Current density & Rotational speed & $\begin{array}{l}0.1 \mathrm{~g} \cdot \mathrm{L}^{-1} \mathrm{PPG}-\mathrm{PEG}-\mathrm{PPG} \\
+0.5 \mathrm{M} \text { glycine }\end{array}$ & Thickness \\
\hline $\mathrm{A} \cdot \mathrm{dm}^{-2}$ & $\mathrm{rpm}$ & $\mathrm{Cr}(\operatorname{mass} \%)$ & $\mu \mathrm{m}$ \\
25 & 1,000 & - & - \\
50 & 1,000 & 13 & 5 \\
75 & 1,000 & 21 & 10 \\
100 & 1,000 & 23 & 13 \\
75 & 2,000 & 18 & 8 \\
100 & 2,000 & 22 & 9 \\
\hline
\end{tabular}

increase of the polarization for the alloy deposition.

The measured thickness of the coatings, deposited under the conditions presented in Table 3 , show an increase of the layer thickness from 5 over 10 to 13 $\mu \mathrm{m}$ with the increase of the current density from 50 over 75 to $100 \mathrm{~A} \cdot \mathrm{dm}^{-2}$, respectively. The thickness value of $13 \mu \mathrm{m}$, for example, obtained after $106 \mathrm{~s}$ of deposition, is close to the thickness value of a layer deposited for $60 \mathrm{~s}$ from the electrolyte containing only PPG-PEG-PPG (Table 1, row 3). This is a clear indication about a lower current efficiency of alloy deposition from the electrolyte containing glycine. 
In contrast to the observed independence of the $\mathrm{Cr}$ content in the alloy form the additive concentration and the current density, a dependence between the metal ions concentration and the concentration of the additives in the electrolyte was established in experiments with different $\mathrm{Zn}(\mathrm{II}): \mathrm{Cr}(\mathrm{III})$ ratios. For example, a PPG-PEG-PPG concentration of $0.1 \mathrm{~g} \cdot \mathrm{L}^{-1}$ in an electrolyte containing $0.4 \mathrm{M} \mathrm{Zn}$ (II) and 0.2 or $0.4 \mathrm{M} \mathrm{Cr}(\mathrm{III})$ ensures $\mathrm{Cr}$ co-deposition, in the high current density range in amounts of about 20 and 30 mass $\%$, respectively. A concentration of $0.6 \mathrm{M} \mathrm{Zn(II)}$ in the electrolyte already requires higher minimum amount of PPG-PEG-PPG $\left(0.2 \mathrm{~g} \cdot \mathrm{L}^{-1}\right)$ for $\mathrm{Cr}$ co-deposition and layer formation. No relation between the $\mathrm{Cr}$ (III) concentration and the co-polymer concentration was established, but between the $\mathrm{Cr}(\mathrm{III})$

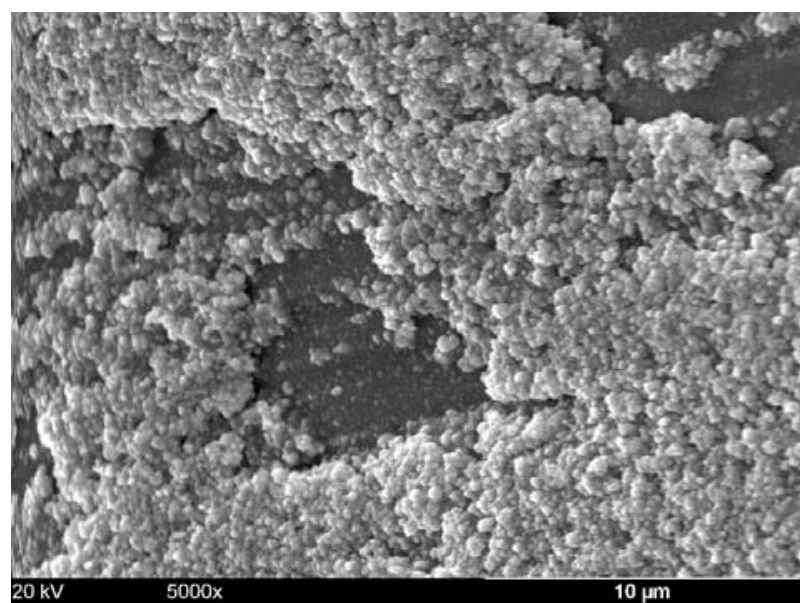

(a)

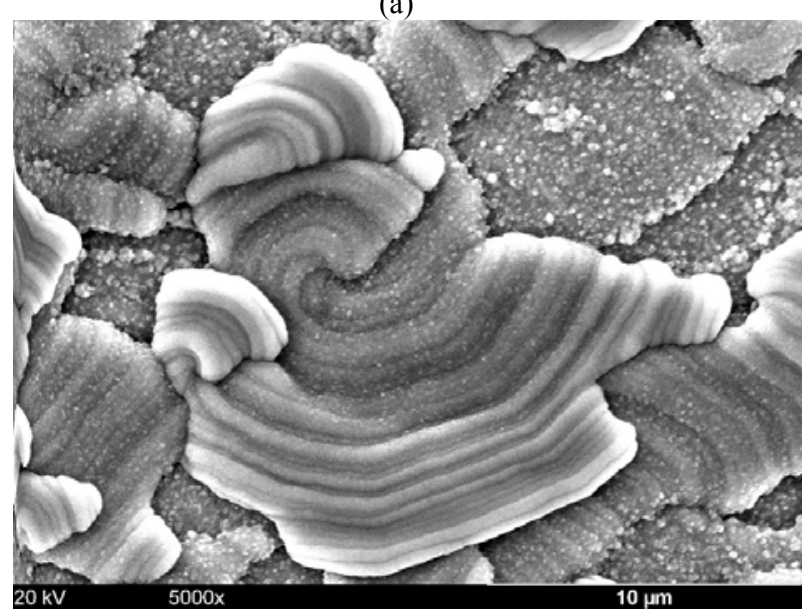

(c) concentration in the electrolyte and that of glycine. For instance, the amount of glycine can be reduced from 0.5 to $0.25 \mathrm{M}$ if $0.2 \mathrm{M} \mathrm{Cr}(\mathrm{III})$ is present in the electrolyte. These results support the assumed main role of the additives, namely, surface active action of the co-polymer (adsorption on the electrode surface) and complex formation of glycine with the metallic ions in the electrolyte. It has been found that a $\mathrm{pH} 2$ of an electrolyte for $\mathrm{Zn}-\mathrm{Cr}$ electrodeposition gives rise to a number of complexes of $\mathrm{Zn}$ (II) and $\mathrm{Cr}$ (III) with glycine in various degrees of protonation [11]. However, glycine-electrode surface active action and interaction/week complexation of the co-polymer with the $\mathrm{Zn}(\mathrm{II})$ in the electrolyte should be considered as well.

The SEM image in Fig. 4a shows irregular coverage

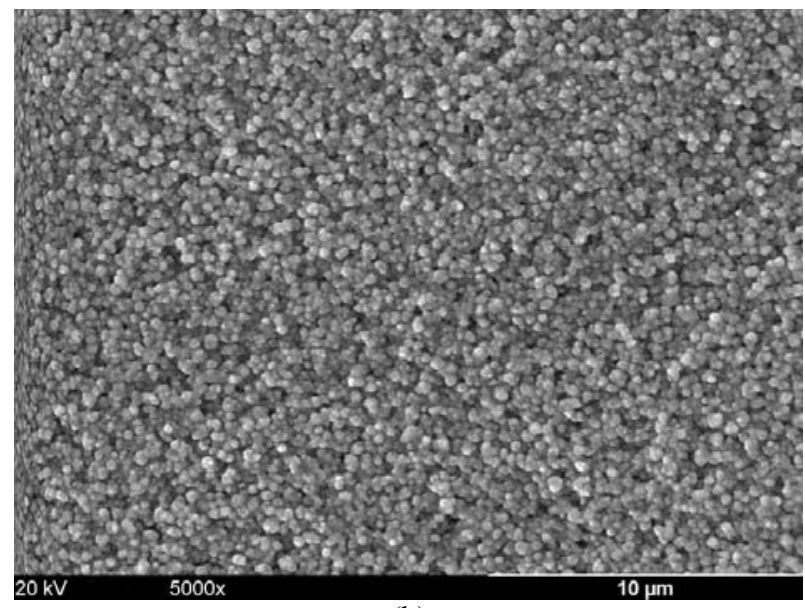

(b)

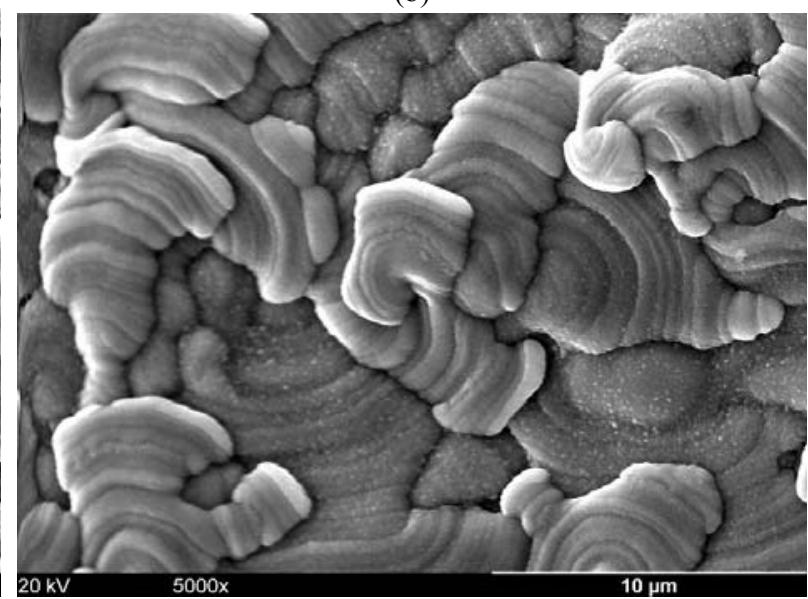

(d)

Fig. 4 Morphology of Zn-Cr coatings deposited from 0.4 SSE + 0.125 g. $\mathrm{L}^{-1}$ PPG-PEG-PPG + 0.5 M glycine at 1,000 rpm for $106 \mathrm{~s}:$ (a) $25 \mathrm{~A} \cdot \mathrm{dm}^{-2}$, (b) $50 \mathrm{~A} \cdot \mathrm{dm}^{-2}$, (c) $75 \mathrm{~A} \cdot \mathrm{dm}^{-2}$, (d) $100 \mathrm{~A} \cdot \mathrm{dm}^{-2}$. (a) to (d) from top to bottom. 
of the substrate surface at the low current density of $25 \mathrm{~A} \cdot \mathrm{dm}^{-2}$. At a current density of $50 \mathrm{~A} \cdot \mathrm{dm}^{-2}$ the surface is completely coated by densely packed polycrystalline particles with a regular shape and size (Fig. 4b).

Polycrystalline agglomerates in the macro-scale, forming a specific pattern appear with further increase of the current density (Figs. 4c and 4d). Similar patterns are also observed at shorter deposition times, Fig. 5a, suggesting regular distribution of $\mathrm{Cr}$ in depth. A mean surface roughness, $\mathrm{Ra}$ of about $0.5 \mu \mathrm{m}$ was measured for the layers shown in Figs. $4 \mathrm{c}, 4 \mathrm{~d}$ and $5 \mathrm{a}$, i.e. the value obtained for coatings deposited from the electrolyte containing only PPG-PEG-PPG. The comparison of Figs. 5a and 3c illustrates the effect of the addition of glycine to the co-polymer containing electrolyte on the alloy morphology. The glycine addition yields denser and smoother coatings, probably because of the deposition under higher polarization.

The effect of the rotational speed on the morphology of the alloy coatings deposited from the electrolyte containing the combined PPG-PEG-PPG and glycine additive can be followed by comparison of the SEM images in Fig. 5.

Variations of the rotational speed of the cylinder electrodes in the $500-3,000 \mathrm{rpm}$ range at a fixed

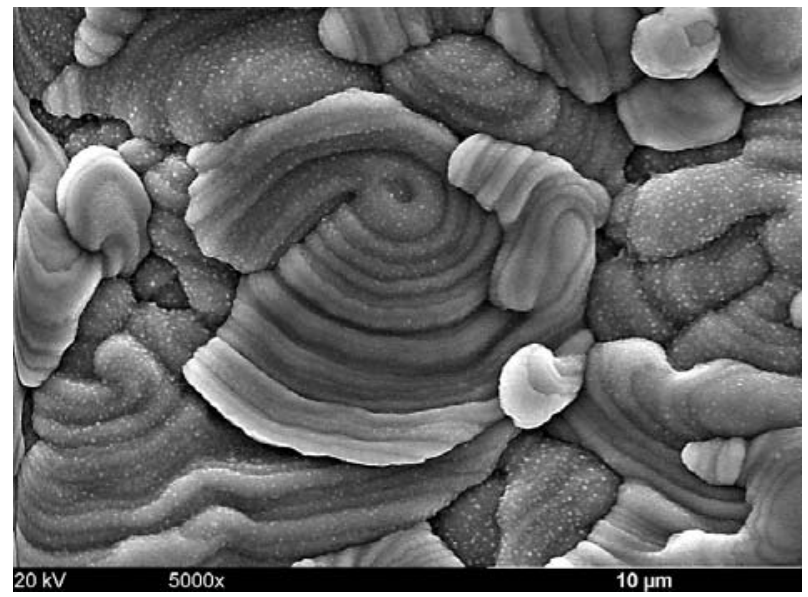

(a) current density showed a decrease of the $\mathrm{Cr}$ content with the increase of the rotation per minute, emphasizing on the effect of the contact time of the reacting species at the cathode over the consumption rate. The increase of the rotational speed is also reflected in a reduced coatings' thickness (Table 3 ).

An increase of the electrolyte temperature from the room temperature to 40,50 and $60{ }^{\circ} \mathrm{C}$ results in a lower $\mathrm{Cr}$ content in the respective coatings; for example: at $500 \mathrm{rpm}, 100 \mathrm{~A} \cdot \mathrm{dm}^{-2}, 40{ }^{\circ} \mathrm{C}, 9.5 \mathrm{mass} \%$ Cr were co-deposited, while at $500 \mathrm{rpm}, 100 \mathrm{~A} \cdot \mathrm{dm}^{-2}$, $60{ }^{\circ} \mathrm{C}$, the amount of $\mathrm{Cr}$ was reduced to about 5 mass\%. The reduction of the $\mathrm{Cr}$ content in the coatings deposited at elevated temperatures could be related to the $\mathrm{Cr}$ (III) chemistry in the electrolytes [15]. It is known that raising the electrolyte temperature results in transformations of the hexa-aquo $\mathrm{Cr}(\mathrm{III})$ complexes and also facilitates $\mathrm{Cr}$ (III) oligomer-/polymer- complex formation, leading to a reduction of the available electroactive, reducible $\mathrm{Cr}$ (III) species. The increase of the electrolyte temperature contributes to brighter and smoother coatings' surfaces.

Fig. 6 presents the appearance of $\mathrm{Zn}-\mathrm{Cr}$ alloy coatings deposited from the basic 0.4 SSE containing PPG-PEG-PPG or PPG-PEG-PPG and glycine.

The current efficiencies for the presented in Fig. 6

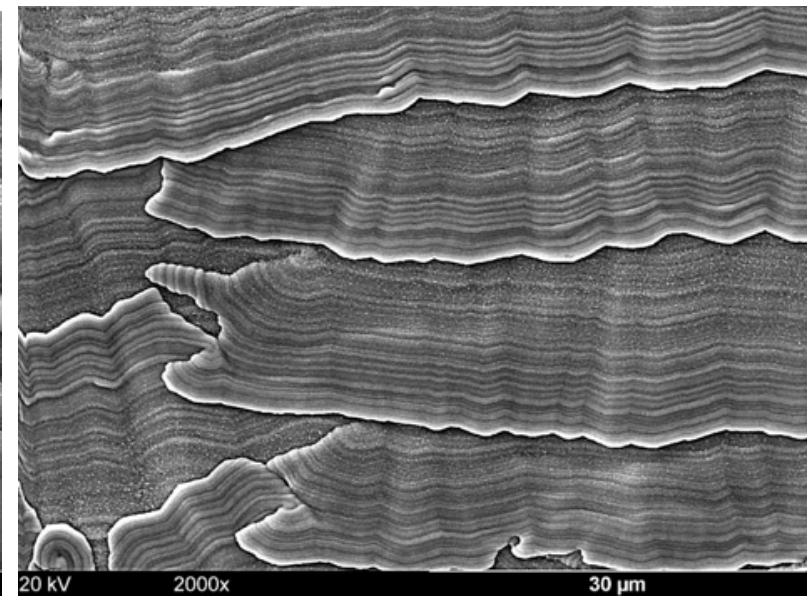

(b)

Fig. 5 Effect of the rotational speed on the morphology of coatings deposited at 1,000 rpm (a) and 2,000 rpm (b) at 100 $\mathrm{A} \cdot \mathrm{dm}^{-2}$, for $80 \mathrm{~s}$ from $0.4 \mathrm{SSE}+0.125 \mathrm{~g} \cdot \mathrm{L}^{-1}$ PPG-PEG-PPG $+0.5 \mathrm{M}$ glycine. (a) to (b) from top to bottom. 


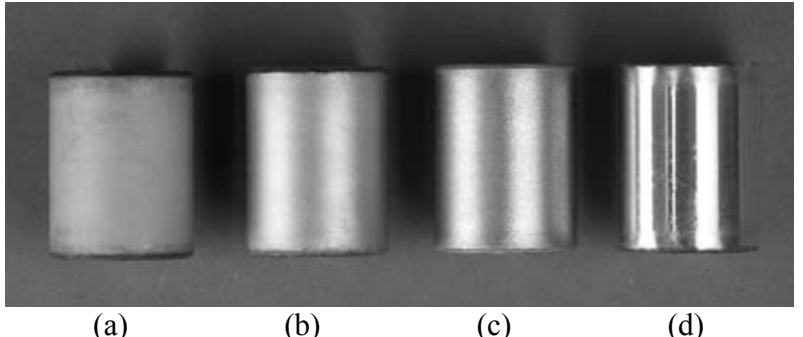

Fig. 6 Appearance of $\mathrm{Zn}-\mathrm{Cr}$ alloy coatings deposited from: (a) 0.4 SSE $+1 \mathrm{~g} \cdot \mathrm{L}^{-1}$ PPG-PEG-PPG and (b, c and d) 0.4 SSE + 0.125 g.L $\mathrm{L}^{-1}$ PPG-PEG-PPG + 0.5 M glycine at: (a) $100 \mathrm{~A} \cdot \mathrm{dm}^{-2}, 1,000 \mathrm{rpm}$ for $80 \mathrm{~s}$, (b) $100 \mathrm{~A} \cdot \mathrm{dm}^{-2}, 1,000 \mathrm{rpm}$ for $80 \mathrm{~s}$, (c) $100 \mathrm{~A} \cdot \mathrm{dm}^{-2}, 2,500 \mathrm{rpm}$ for $80 \mathrm{~s}$ and (d) electrolyte diluted also in respect to $\mathrm{Cr}$ (III) (0.2 M Cr(III)), $75 \mathrm{~A} \cdot \mathrm{dm}^{-2}, 1,000 \mathrm{rpm}$ for $106 \mathrm{~s}$.

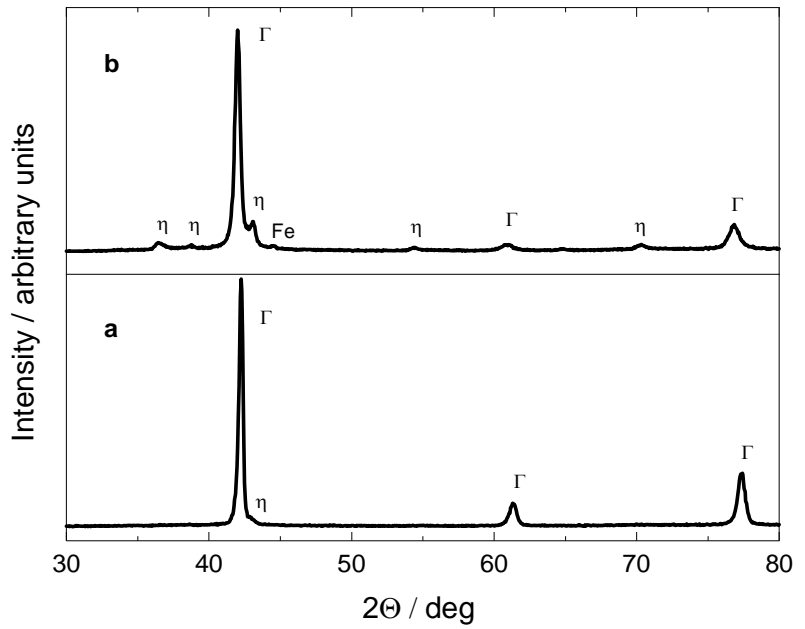

Fig. 7 XRD patterns of $\mathrm{Zn}-\mathrm{Cr}$ alloy coatings: (a) $\mathrm{Zn}-32 \% \mathrm{Cr}$ alloy coating deposited at $75 \mathrm{~A} \mathrm{dm}^{-2}, 1,000 \mathrm{rpm}$, $106 \mathrm{~s}$ from $0.4 \mathrm{SSE}+0.125 \mathrm{~g} \cdot \mathrm{L}^{-1}$ PPG-PEG-PPG and (b) $\mathrm{Zn}-21 \% \mathrm{Cr}$ alloy coating deposited at $75 \mathrm{~A} \cdot \mathrm{dm}^{-2}, 1,000 \mathrm{rpm}$, $106 \mathrm{~s}$ from 0.4 SSE + 0.125 g. $\mathrm{L}^{-1}$ PPG-PEG-PPG + 0.5 M glycine.

alloy coatings are as follow: (a) $54 \%$ for $\mathrm{Zn}-32 \% \mathrm{Cr}$, (b) $42 \%$ for $\mathrm{Zn}-22 \% \mathrm{Cr}$, (c) $49 \%$ for $\mathrm{Zn}-21.5 \% \mathrm{Cr}$ and (d) $46 \%$ for $\mathrm{Zn}-9 \% \mathrm{Cr}\left(\mathrm{R}_{\mathrm{a}}\right.$ of $\left.0.2 \mu \mathrm{m}\right)$.

\subsubsection{Composition of the Alloy Coatings}

The XRD examination of a $\mathrm{Zn}-32 \% \mathrm{Cr}$ coating, deposited from the electrolyte containing the co-polymer shows almost pure $\Gamma-(\mathrm{Zn}, \mathrm{Cr})$ phase (Fig. 7a), a solid solution with a body centered cubic sub-cell [4]. The XRD pattern indicates, by a shoulder at $43.23^{\circ}$ a small amount of hexagonal $\eta-(\mathrm{Zn}, \mathrm{Cr})$ phase. The lower $\mathrm{Cr}$ content, of about 20 mass $\%$ in the coatings from the electrolyte containing the combined additive is reflected in an increase of the relative share of the hexagonal $\eta-(\mathrm{Zn}, \mathrm{Cr})$ phase (Fig. $7 b)$. The detection of Fe from the substrate correlates with the lower current efficiency of the alloy deposition from this electrolyte.

No presence of $\mathrm{C}$ in the coatings deposited from the 0.4 SSE (without additives) was detected by EDX. Incorporation of 1.8 and 2.5 mass $\% \mathrm{C}$ was registered after alloy deposition from electrolytes containing 0.1 and $1.0 \mathrm{~g} \cdot \mathrm{L}^{-1}$ PPG-PEG-PPG, respectively. When the electrolyte contains $0.1 \mathrm{~g} \cdot \mathrm{L}^{-1}$ PPG-PEG-PPG and 0.5 $\mathrm{M}$ glycine the amount of $\mathrm{C}$ in the coating is 2.4 mass\%, indicating that also $\mathrm{C}$ from glycine and/or glycine species incorporates as well.

It is worth mentioning that the chemical state of $\mathrm{Cr}$ for "as deposited" alloy coatings from an electrolyte having the same base composition $[4,16]$ and coatings subjected to anodic or corrosion treatment has been determined by XPS to be $\mathrm{Cr}$ (III) compounds and metallic $\mathrm{Cr}$ in depth [11,13].

\subsection{Galvanostatic Deposition on Flat Samples}

The RCE experiments showed that homogeneous and shiny $\mathrm{Zn}-\mathrm{Cr}$ alloy coatings with a relatively high $\mathrm{Cr}$ content can be deposited under the conditions of high flow velocity of the electrolyte and high current density, respectively from an electrolyte containing PPG-PEG-PPG co-polymer additive in a very low concentration of $0.1 \mathrm{~g} \cdot \mathrm{L}^{-1}$.

The alloy deposition process under galvanostatic conditions was further investigated on flat electrodes at room temperature.

\subsubsection{Effect of the Current Density}

From the basic 0.6 SSE without an additive and without agitation, up to a current density of $10 \mathrm{~A} \cdot \mathrm{dm}^{-2}$ no $\mathrm{Cr}$ in the coatings was registered. Fig. 8 presents the appearance of the deposits at two current densities.

The addition of PPG-PEG-PPG to the 0.6 SSE allows deposition of alloy coatings at a current density as low as $5 \mathrm{~A} \cdot \mathrm{dm}^{-2}$ (Table 4).

The co-polymer sharply reduces the current efficiency 


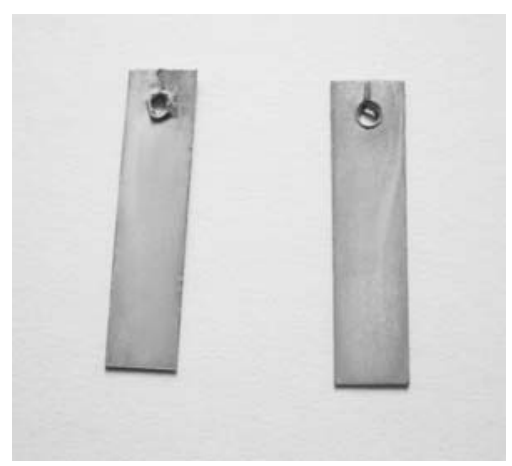

Fig. 8 Appearance of coatings deposited from 0.6 SSE for 5 min. From left to right: at $5 \mathrm{~A} \cdot \mathbf{d m}^{-2}$ and at $10 \mathrm{~A} \cdot \mathbf{d m}^{-2}$.

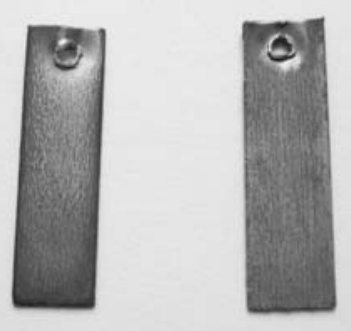

Fig. 9 Appearance of coatings deposited from 0.6 SSE + $0.5 \mathrm{~g} \cdot \mathrm{L}^{-1}$ PPG-PEG-PPG for $5 \mathrm{~min}$. From left to right: at 5 $\mathbf{A} \cdot \mathbf{d m}^{-2}$ and at $10 \mathrm{~A} \cdot \mathbf{d m}^{-2}$.

as expected also from the voltammogram in Fig. 1 and Table 1. Fig. 9 presents the appearance of the deposits at the corresponding current densities.

Thus, at a low current density alloy coatings with $\mathrm{Cr}$ content in the desired range of about 12 mass $\%$ were obtained. However, the quality of the coatings is unsatisfactory.

\subsubsection{Effect of the Electrolyte Composition}

The decrease of the concentration of $\mathrm{Zn}(\mathrm{II})$ in the electrolyte from $0.6 \mathrm{M}$ to $0.4 \mathrm{M}$ facilitates the $\mathrm{Cr}$ co-deposition with $\mathrm{Zn}$. Analysis of samples deposited under galvanostatic conditions, without agitation from the 0.4 M SSE showed higher $\mathrm{Cr}$ content in the coating compared to that in a coating obtained from the 0.6 SSE. Moreover, co-deposited $\mathrm{Cr}$ is registered from the basic electrolyte without additives (Table 5).

The addition of $1 \mathrm{~g} \cdot \mathrm{L}^{-1}$ PPG-PEG-PPG to the diluted in respect to $\mathrm{Zn}(\mathrm{II})$ electrolyte (0.4 SSE) allows deposition of coatings with $\mathrm{Cr}$ content up to 27 mass \%. Glycine as an only additive, similarly to the deposition on RCE did not facilitate the $\mathrm{Cr}$ co-deposition with $\mathrm{Zn}$. The consecutive addition of glycine to the PPG-PEG-PPG containing electrolyte however reduces the $\mathrm{Cr}$ content almost twice (Table 5).

\subsubsection{Effect of the Hydrodynamic Conditions}

Besides the additives, an important factor affecting the deposition process is the hydrodynamic regime, as proven also by the RCE experiments. Methods to ensure movement at the electrode-electrolyte interface used in the classical electrogalvanization include agitation by air and rack movement. Results from deposition experiments under such conditions for a selected electrolyte composition are presented in Table 6.

Fig. 10 presents the appearance of the corresponding coatings. The electrolyte agitated by air shows promising results in respect to $\mathrm{Cr}$ content and appearance of the coatings.

Nevertheless, the layer thickness is strongly reduced. A simple bending test (to $90^{\circ}$, repeatedly) showed no flaking, indicating a good adhesion of the coating to the substrate.

The corrosion-electrochemical performance and the properties of the coatings are going to be subjects of discussion in a following publication.

Table 4 Effect of $0.5 \mathrm{~g} \cdot \mathrm{L}^{-1}$ PPG-PEG-PPG on the $\mathrm{Cr}$ content and thickness of alloys deposited on flat steel samples at different current densities for $5 \mathrm{~min}$, without agitation, at room temperature.

\begin{tabular}{llll}
\hline & $0.6 \mathrm{SSE}$ & $0.6 \mathrm{SSE}+0.5 \mathrm{PPG}-\mathrm{PEG}-\mathrm{PPG}$ \\
\cline { 2 - 4 } & $5 \mathrm{~A} \cdot \mathrm{dm}^{-2}$ & $5 \mathrm{~A} \cdot \mathrm{dm}^{-2}$ & $10 \mathrm{~A} \cdot \mathrm{dm}^{-2}$ \\
\hline Cr content in the alloy / mass $\%$ & 0.0 & 12.3 & 12.6 \\
Thickness of the coating / $\mu \mathrm{m}$ & 4.4 & 1.1 & 1.7 \\
\hline
\end{tabular}


Table 5 Effect of PPG-PEG-PPG and glycine on the Cr content and thickness of alloys deposited on flat steel samples at 20 A. $\mathrm{dm}^{-2}$ for $90 \mathrm{~s}$, without agitation, at room temperature.

\begin{tabular}{llll}
\hline & $0.4 \mathrm{SSE}$ & $\begin{array}{l}0.4 \mathrm{SSE} \\
+1.0 \text { PPG-PEG-PPG }\end{array}$ & $\begin{array}{l}0.4 \mathrm{SSE} \\
+1.0 \text { PPG-PEG-PPG } \\
+0.5 \text { glycine }\end{array}$ \\
\hline Cr content in the alloy $(\mathrm{mass} \%)$ & 0.5 & 27.4 & 15.1 \\
Thickness of the coating $(\mu \mathrm{m})$ & 2.8 & 2.4 & 1.6 \\
\hline
\end{tabular}

Table 6 Effect of the hydrodynamic conditions on the Cr content and thickness of alloys deposited on flat steel samples at 20 $\mathrm{A} \cdot \mathrm{dm}^{-2}$ for $90 \mathrm{~s}$, at room temperature.

\begin{tabular}{llll}
\hline 0.4 SSE +0.5 PPG-PEG-PPG +0.5 Glycine & No agitation & Agitation by air & Rack movement \\
\hline Cr content in the alloy $($ mass $\%)$ & 18.2 & 11.3 & 9.3 \\
Thickness of the coating $(\mu \mathrm{m})$ & 2.4 & 0.8 & 0.9 \\
\hline
\end{tabular}

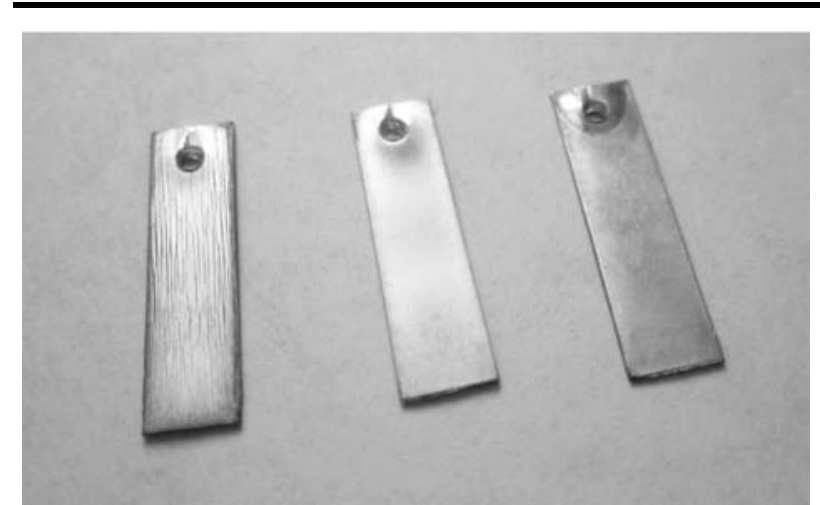

Fig. 10 Appearance of coatings deposited from 0.4 SSE + $0.5 \mathrm{~g} \cdot \mathrm{L}^{-1}$ PPG-PEG-PPG $+0.5 \mathrm{M}$ glycine. From left to right: no agitation, agitation by air, rank movement.

\section{Conclusions}

Exploration of the suitability of PPG co-polymer additive and optimization of parameters for $\mathrm{Zn}-\mathrm{Cr}$ alloy electrodeposition was performed.

A low concentration of the PPG-PEG-PPG co-polymer additive in the electrolyte $\left(0.1 \mathrm{~g} \cdot \mathrm{L}^{-1}\right)$ allows deposition of $\mathrm{Zn}-\mathrm{Cr}$ alloy coatings containing up to 33 mass\% Cr. The electrolyte composition including the combined PPG-PEG-PPG and glycine additive produces coatings with shiny surfaces ( $\mathrm{Ra}$ as low as $0.2 \mu \mathrm{m}$ ) and lower $\mathrm{Cr}$ content. The current efficiency of the alloy deposition process is within the $40-60 \%$ range.

Depending on the electrolyte composition and the hydrodynamic conditions a low current density within the $5-20 \mathrm{~A} \cdot \mathrm{dm}^{-2}$ range can be used for the deposition of dense coatings with $\mathrm{Cr}$ content in the desired range of about 10 mass $\%$.

The electrolyte containing PPG-PEG-PPG co-polymer additive shows promising results with respect to the alloy deposition, which makes it a good candidate for $\mathrm{Zn}-\mathrm{Cr}$ alloy batch galvanizing. However, further investigations and optimization of the deposition process are necessary.

\section{Acknowledgments}

The investigations were performed with the support of the Austrian Science Foundation FFG and the government of Lower Austria in the frame of the COMET program. I would like to thank Prof. M. Monev for his cooperation in the preparation of the present publication, to Prof. H. Kronberger for his support and to DI G. Wolf for the SEM imaging.

\section{References}

[1] Steck, T., Gerdenitsch, J., Tomandl, A., Achleitner, W., Faderl, J. and Lavric T. et al. 2011. "Zinc-Chromium Coated Steel Sheet: Properties and Production." In Proceeding of GALVATECH 8th International Conference on Zinc and Zinc Alloy Coated Steel Sheet, IAM, 1133-40.

[2] Akiyama, T., Kobayashi, S., Ki, J., Ohgai, T. and Fukushima, H. 2000. "Role of Polyethylene Glycol in Electrodeposition of Zinc-chromium Alloys." J. Appl. Electrochem. 30: 817-22.

[3] Boiadjieva, Tz., Monev, M. and Raichevski, G. 2001. "Electrodeposition of Zinc-Chromium Alloys." U.P.B. Sci. Bull. Series B 63: 135-40.

[4] Boiadjieva, Tz., Kovacheva, D., Petrov K., Hardcastle S., Sklyarov, A. and Monev, M. 2004. "Electrodeposition, Composition and Structure of Zn-Cr Alloys." J. Appl. Electrochem. 34: 315-21.

[5] Boiadjieva, Tz., Monev, M., Kronberger, H., Tomandl, A., Petrov, K. and Angerer, P. 2010. "Effect of PEG 400 
on Zn-Cr Alloy Electrodeposition.” J. Electrochem. Soc. 157: D159-67.

[6] Boiadjieva, Tz., Kovacheva, D., Lyutov, L. and Monev, M. 2008. "Deposition of Zn-Cr Alloy Coatings from Sulfate Electrolyte. Effect of Polypropylene Glycol 620 and Glycine and Combination Thereof." J. Appl. Electrochem. 38: 1435-43.

[7] Muresan, L. and Varvara, S. 2005. Metal Electrodeposition. M. Nunez (Ed.), Nova Science, New York.

[8] Plieth, W. 2008. Electrochemistry for Material Science Elsevier, Amsterdam.

[9] Heyrovsky, J. "Electrode Progresses." Discuss. Faraday Soc. 1: 212-23.

[10] Sano, H., Yoshida, H., Oosugi, T., Murakami, T., Takagawa, Y. and Mizutani, G. et al. 2007. "Effect of Polymer Adsorption on the Water Structure at the Quartz/Water Interface Studied by Optical Sum Frequency Generation.” Surf. Science 601: 5173-9.

[11] Boiadjieva, Tz., Kovacheva, D., Petrov, K., Hardcastle, S. and Monev, M. 2004. "Effect of Anodic Treatment on the Composition and Structure of Electrodeposited $\mathrm{Zn}-\mathrm{Cr}$ Alloy Coatings." Corr. Sci., 46: 681-95.

[12] Boiadjieva, Tz., Monev, M. and Raichevski, G. 2000. "Electrodeposition and Corrosion Behaviour of $\mathrm{Zn}-\mathrm{Cr}$ Electrodeposits." In Proceedings of the VII International Corrosion Symposium 434-41.

[13] Boiadjieva, T., Petrov, K., Raichevski, G. and Monev, M. 2006. "Changes in Composition and Structure of Electrodeposited $\mathrm{Zn}$-Cr Alloy Coatings Resulting in Corrosion Treatment." Trans. IMF 84 (6): 313-9.

[14] Berezin, N., Gudin, N., Chevela, V. and Filippova, A. 1992. "Effect of Complexation on Electroplating of Zinc-Chromium Alloys from Acidic Glycine Baths." Translated from Zastita Metallov 28 (6): 961-6.

[15] Rollinson, C. 1973. The Chemistry of Chromium, Molybdenum and Tungsten, Pergamon Press.

[16] Itani, H., Duchoslav, J., Arndt, M., Steck, T., Gerdenitsch, J. and Faderl, J. et al. 2012. "X-Ray Photoelectron and Scanning Auger Electron Spectroscopy Study of Electrodeposited ZnCr Coatings on Steel." Anal. Bioanal. Chem. 403 (3): 663-73. 